\title{
Vulnerability, Insecurity and the Pathologies of Trust and Distrust
}

Catriona Mackenzie, Philosophy Department, Macquarie University, Sydney

catriona.mackenzie@mq.edu.au

This article will appear in the Special Issue of the International Journal of Philosophical Studies on Vulnerability and Trust, Volume 28, Issue V, November 2020, edited by Maria Baghamian, Danielle Petherbridge, Rowland Stout

\section{Abstract}

While some trust theorists have adverted to the vulnerabilities involved in trust, especially vulnerability to betrayal, the literature on trust has not engaged with recent work on the ethics of vulnerability. This paper initiates a dialogue between these literatures, and in doing so begins to explore the complex interrelations between vulnerability and trust. More specifically, it aims to show how trust can both mitigate and compound vulnerability. Through a discussion of two examples drawn from literary sources, the paper also investigates the effects of pathogenic vulnerability on the psychic economies of trust and distrust.

Recent work on ontological vulnerability has sought to counter the association of vulnerability with suffering and risk of exposure to harm. While not denying that these more negative associations are part of the meaning of vulnerability, theorists such as Erinn Gilson (2011), have also pointed to the positive dimensions of vulnerability: "Being vulnerable makes it possible for us to suffer, to fall prey to violence and be harmed, but also to fall in love, to learn, to take pleasure and find comfort in the presence of others, and to experience the simultaneity of these feelings" (310). On Gilson's account, ontological vulnerability, as a shared human condition, should be understood primarily as a condition of "ambivalent potential", of "openness to being affected and affecting in turn" (310). This openness, she claims, is a constitutive condition of our human embodiment, sociality and affectivity.

In a related vein, Carla Bagnoli (2018) characterises emotional vulnerability as "the capacity to be emotionally affected and to emotionally affect others" (208). Taking intimate love relations as a primary exemplar of emotional vulnerability Bagnoli, like Gilson, points to the ambivalence of this kind of vulnerability. A loving relation makes lovers emotionally vulnerable to each other. However, this vulnerability should not be regarded as a constraint on their agency. Rather, the transformative power of 
love to re-shape our identities and open us to new possibilities and opportunities has the potential to "expand[s] the sphere of our agency and enhance[s] our capacities for agency" (212). Nevertheless, our openness to being reciprocally affected by the other also makes us vulnerable to circumstantial luck, and to emotional hurt and pain.

In my view, Gilson and Bagnoli are correct to draw attention to the ambivalence of ontological vulnerability and I am sympathetic to their insistence that theorists of vulnerability should not ignore the positive dimensions of vulnerability. The ambivalence of vulnerability is nowhere more evident than in the complex relations between vulnerability and trust. Trust is a response to ontological vulnerability. In trusting others we mitigate the potential risks and insecurity arising from our vulnerability and from our inescapable dependence on others. At the same time, in trusting others we make ourselves vulnerable to them and hence to the possible betrayal, abuse, or exploitation of our trust. Our assessments of another's trustworthiness, that is, of whether our trust is warranted and wise, are attempts to navigate the ambivalences of the vulnerability involved in trust. While trust theorists have adverted to some of the vulnerabilities involved in trust, especially vulnerability to betrayal, these brief references have not been informed by the literature on the ethics of vulnerability. The first aim of this paper is to show how recent work on vulnerability can help to illuminate the complex interrelations between vulnerability and trust; more specifically, to show how trust can both mitigate and compound vulnerability.

In explicating the ways that trust can compound vulnerability, I will draw on recent work on pathogenic vulnerability (Mackenzie, Rogers, Dodds 2014). Pathogenic vulnerability, I argue, can engender pathologies of trust and distrust that are selfreinforcing and self-perpetuating, thereby functioning to compound existing vulnerabilities. The second aim paper is to explore these effects of pathogenic vulnerability and the insecurities they generate on the psychic economies of trust and distrust.

In the first section, I begin with an overview of debates in the literature concerning the meaning, scope and usefulness of the concept of vulnerability and then outline the vulnerability taxonomy I have developed elsewhere to reconcile the tensions between 
competing accounts. ${ }^{1}$ The second section explores the ambivalence of the vulnerability involved in relations of trust, with reference to Annette Baier's (1986) influential analysis of trust, and Karen Jones' (1996, 2004, 2019) affective attitude account of trust. In the third section, I discuss two examples that illustrate how pathogenic forms of vulnerability and the insecurities they generate can engender pathologies of trust and distrust.

\section{1: Vulnerability}

In the recent literature, there has been considerable debate about the meaning, scope and usefulness of the concept of vulnerability. With respect to meaning and scope, theorists are divided about whether vulnerability should be understood as ontological and universal, or relational and context-specific. Those who favour an ontological account understand vulnerability as universal and as inherent to the human condition (see e.g. Butler 2004; Fineman 2008, 2010; MacIntyre 1999; Nussbaum, 2006; Ricoeur 2007; Turner 2006). On this view, we are vulnerable because we are finite, embodied, social, beings with physical and emotional needs, and it is in virtue of our vulnerability and neediness that we are both dependent on others- to varying degrees at various points in our lives - and vulnerable to their actions and choices.

Ontological accounts typically link the concept of vulnerability with its etymological derivation from the Latin word vulnus, meaning "wound", and hence focus on the associations between vulnerability and susceptibility to harm and suffering. However, as noted above, theorists such as Gilson (2011) and Bagnoli (2018) highlight the ambivalent potential of ontological vulnerability. As a condition of openness to being affected and affecting in turn, although vulnerability does make us susceptible to suffering, violence and harm, it also enables powerful and transformative physical and emotional experiences, such as love, pleasure and joy.

With respect to the usefulness of the concept, proponents of the ontological view claim that the normative significance of vulnerability, need and dependency has been overlooked by moral and political theory, which has been premised on a distorted,

\footnotetext{
${ }^{1}$ For discussions of the taxonomy, see Rogers, Mackenzie, Dodds (2012); Mackenzie, Rogers, Dodds (2014). Mackenzie (2014); Mackenzie (2017), Mackenzie (forthcoming). The discussion in the first section of the paper adapts some material from these articles.
} 
overly rationalistic conception of human agency (see e.g. Kittay 1999; Nussbaum 2006; MacIntyre 1999; Miller 2012). Gilson (2011) suggests that motivated ignorance and disavowal of ontological vulnerability perpetuates the illusion of the invulnerable, self-sufficient, independent subject of neo-liberal capitalism; a claim that echoes Martha Fineman's (2008) critique of the 'autonomy myth' and her arguments for reframing social and legal policy around the figure of the 'vulnerable subject'. Some critics object, however, that the concept of ontological vulnerability is vacuous because trivially true and they are dubious of its explanatory value for moral theorising (see e.g. Hurst, 2008; Wrigley 2015, 482). Ontological views have also been criticised for obscuring the diverse, context-specific sources of vulnerability and the specific responsibilities and obligations they generate (see e.g. Hurst 2008, Luna 2009, Kohn 2014), and the systemic injustices and inequalities that render some persons or groups more vulnerable than others (Coyle 2016).

Proponents of relational, context-specific views propose more restricted analyses of the meaning and scope of the concept, arguing that its value in moral theorising is to highlight the contingent and relational susceptibility of particular persons or groups to specific harms or threats to their interests. On this view, while everyone is potentially vulnerable to such harms or threats, some persons or groups have diminished capacity to safeguard their interests relative to others (see e.g. Goodin 1985; Nickel 2006), are more susceptible to exploitation (see e.g. Macklin 2003), are more likely not to have their interests fairly and justly taken into account (Martin et. al. 2014), or to be the victims of systemic injustice and inequality (see e.g. Coyle 2016). Thus, whereas the ontological view emphasises our common embodied humanity and equal susceptibility to suffering, the relational, context-sensitive view stresses the ways in which various inequalities, for example in resources or power, make some agents the 'more than ordinarily vulnerable' (Sellman 2005) - especially susceptible to being wronged by others.

In my view, it is a mistake to view the ontological and relational conceptions as opposed. As I have argued elsewhere (Mackenzie 2017), the concept of ontological vulnerability, and related concepts such as needs and dependency, draw attention to morally salient features of our common humanity, features that are entwined with, rather than distinct from, our capacities for rational agency. How this shared 
ontological vulnerability is manifested and experienced, however, is shaped by agents' environments and social relationships. To understand the ethical responsibilities generated by vulnerability, we need to focus on its context-specific manifestations in the lives of individual agents and social groups. We also need to make salient how some of these vulnerabilities are caused by systemic structural inequality and injustice. The taxonomy of vulnerability aims to account for the multifaceted dimensions of vulnerability by distinguishing different sources (inherent, situational and pathogenic) and states (potential and occurrent) of vulnerability.

Inherent vulnerability refers to sources of vulnerability that are intrinsic to the human condition: our embodiment, our neediness, our dependence on others, and our affective and social natures. Inherent vulnerability cannot be eliminated, nor should we want to eliminate it, since it is constitutive of our humanity and the source of the most profound human emotions and experiences. Nevertheless, our inherent vulnerability also exposes us to suffering, harm and wrongs at the hands of others. Inherent vulnerability is thus inescapably ambivalent, both the source of our most profound and positive experiences as embodied social agents and also of potential suffering. The exposure to suffering arising from embodiment, need and dependency varies in degree over the course of a human life: young children, the infirm elderly, people with chronic physical or mental ailments are typically more exposed to the harms and insecurities that ensue if their vulnerability is not mitigated through the provision of care and social support. Care is thus an ethical response to inherent vulnerability. ${ }^{2}$

The notion of situational vulnerability draws attention to the relational and contextspecific factors that shape the ways in which inherent vulnerability might be manifested and experienced by individuals, communities and social groups. Such factors are many and varied and may include environmental conditions, social norms and practices, the available material, physical and social resources, institutional structures (political, economic, legal), as well as an individual's specific situation or needs. To be effective, it is critical that moral responses aimed at mitigating the harms of vulnerability are attentive to these situational factors. Since vulnerability can

\footnotetext{
${ }^{2}$ See Miller (2012) and Mackenzie (2017) for detailed arguments for this claim.
} 
sometimes engender a troubling sense of powerlessness, insecurity, loss of control, or loss of agency, it is also critical that interventions triggered in response to vulnerability should aim to enable or restore, to the greatest extent possible, the autonomy of the affected persons or groups, even if in some situations, such as incapacitating illness, this sense of powerlessness cannot necessarily be remedied (Hoffmaster 2006). ${ }^{3}$

It is important to stress that inherent and situational vulnerability intersect in complex ways, as is shown by the example of homelessness. Because one of our basic needs is the need for adequate housing or shelter, all human beings are inherently vulnerable to suffering the harms and insecurities arising from homelessness. Hence we are all potentially vulnerable to homelessness. However, clearly we are not all equally occurrently vulnerable. People with access to secure sources of income, adequate housing, and strong family and social support are unlikely to be exposed to these harms and insecurities. The resources available in their relational and social contexts thus make them resilient to the potential vulnerability of homelessness. By contrast, people who have lost their jobs or are in precarious employment and have little or no family support, women and children who experience domestic violence, those with untreated mental health or substance abuse issues, are typically occurrently highly vulnerable to the harms and insecurities of homelessness.

What this example further shows is the extent to which many of these harms and insecurities are avoidable. The notion of pathogenic vulnerability functions as a way of identifying what Robert Goodin refers to as "all those morally unacceptable vulnerabilities and dependencies which we should, but have not yet managed to, eliminate" $(1985,203)$. Pathogenic vulnerability refers to a sub-set of situational vulnerabilities that are caused by morally dysfunctional, oppressive or dominating social relationships, or by remediable structural inequality and injustice. It also refers to vulnerabilities that are caused by (sometimes well-intentioned) interventions to remediate vulnerability. A young teenager who was being sexually abused at home by a relative and is now homeless, experiences pathogenic vulnerability. This

\footnotetext{
${ }^{3}$ See (Mackenzie 2014) for an argument to the effect that interventions to remediate vulnerability should be guided by the aim of fostering autonomy and enhancing capabilities.
} 
vulnerability may be further compounded by an intervention designed to remediate that vulnerability, such as housing in a shelter for young people if, for example, she develops a drug addiction or is exposed to further abuse and violence while living in the shelter.

The work of Wolff and de Shalit (2007) on corrosive disadvantage helps to clarify the complex interactions between different sources of vulnerability and insecurity. Wolff and de Shalit analyse disadvantage in terms of insecurity of functioning across a range of functionings. ${ }^{4}$ People who are disadvantaged experience not only insecurity of functioning, but also lack genuine opportunities for secure functionings. Moreover, this insecurity and lack of genuine opportunity typically affects not just one functioning but a clustering of functionings, with cumulative effects over time. An example of such clustering is the way over time unemployment can lead to homelessness, and then loss of friendship networks, then ill health (Wolff and de Shalit 2007, 120). The concept of "corrosive disadvantage" refers to the way in which poor or insecure functioning in one domain can cause poor or insecure functionings in other domains, as in this example. Wolff and de Shalit further argue that disadvantage typically exposes people to risks that those who are advantaged do not face and that taking these risks can generate corrosive disadvantage when the risks taken in an attempt to secure one functioning then jeopardises other functionings. They refer to this kind of risk taking as "inverse cross category risk" (70).

In contexts where vulnerability is associated with disadvantage, being vulnerable might be understood as being at increased risk of insecurity of functionings, where the source of that insecurity is likely to be some combination of inherent, situational and pathogenic vulnerability. In the example of the dynamic clustering over time of unemployment, homelessness, loss of social networks and ill health, the initial situational vulnerability of the unemployed person exposes her to pathogenic forms of vulnerability (homelessness and social isolation), which then increases her inherent vulnerability (illness). A key feature of pathogenic vulnerability is that it compounds the sense of powerlessness, insecurity and compromised agency that often

\footnotetext{
${ }^{4}$ Wolff and de Shalit distil Nussbaum's (2006) list of ten capabilities into six central functionings: life, bodily health, bodily integrity, affiliation, control over one's environment, and sense, imagination and thought $(2007,106)$.
} 
accompanies occurrent vulnerability, leading to feelings of humiliation, shame, disrespect and loss of dignity.

In the third section of the paper, I draw on this taxonomy to investigate some of the ways that inherent, situational and pathogenic vulnerability and associated insecurities can generate pathologies of trust and distrust. Before turning to that argument, in the following section I discuss Baier's (1986) and Jones' (1996, 2004, 2019) analyses of trust to explore the interrelations between vulnerability, trust and distrust. ${ }^{5}$

\section{2: Trust and Distrust}

Baier's analysis of trust is motivated by a critique of the contractarian assumptions implicit in much contemporary moral theorising. Contractarians, she argues, take voluntary, explicit agreements between non-intimate adults who are roughly equal in power as 'the paradigm source of moral obligation' $(1986,247)$. This assumption not only overlooks the extent to which contracts rely on background climates of trust. More importantly, it ignores the unequal relations of power, dependency and need that characterise many human relationships. Given the inescapability of need and dependency, we cannot thrive or indeed survive without trusting others whether intimates or strangers, and so trust is essential to human life and of core importance to morality. However, not all trust is morally decent, especially in contexts of power inequality. Thus, trust is ambivalent: we need to be judicious in whom we trust and with what, because while trust is a response to ontological vulnerability it also exposes us to a special kind of vulnerability.

Although Baier discusses the special vulnerability involved in trust and points to the ontological vulnerability that makes trust essential, her primary focus is on theorising trust rather than vulnerability. In what follows, I discuss Baier's analysis of trust and

\footnotetext{
${ }^{5}$ Since the publication of Baier's 'Trust and Anti-trust' (1986), the literature on trust has grown exponentially. My discussion in the following section does not pretend to do justice to the range of issues raised in philosophical debates about trust over the last three decades. Rather, since my aim is to explore the interrelations between vulnerability and trust, and since Baier and Jones have said more about this than most trust theorists, my discussion focuses on their views. For a comprehensive overview of philosophical debates about trust, see McLeod (2020).
} 
her moral test for trust and in doing so tease out in more detail the interrelations between trust and vulnerability.

Baier analyses trust as a three-place relation between truster (A), trusted (B), and something of value $(\mathrm{C})$, the care of which the truster entrusts to the trusted. Thus, I might trust my house-sitter to take care of my house while I am on holiday, my son might trust me to look after his children for the day, a cancer sufferer might trust her doctor to care for her health. According to Baier, trust in another involves more than relying on the other's competence; it also involves reliance on their attitude of (at least minimal) good will toward one $(1986,234)$. This kind of reliance points to one aspect of the special vulnerability involved in trust: trusters are vulnerable to the limits of the trusted's good will and hence open themselves to the risk of harm or betrayal by the trusted. ${ }^{6}$ According to Baier, trust involves an acceptance of this vulnerability: 'trust... is accepted vulnerability to another's possible (but not expected) ill will (or lack of good will) toward one' (235).

Another aspect of the vulnerability involved in trust relates to the discretionary power vested in the trusted by the truster. In entrusting another to care for something of value to her, the truster vests the trusted with the discretion to judge how best to care for that thing. I might give my house-sitter instructions about how to use the heating and household appliances and how often to water the garden, but if I trust him I will leave it to him to make decisions about when to turn on the heating, what temperature to set the thermostat, whether or not to water the garden depending on how wet or dry the weather is. Similarly, in entrusting his children to my care, my son must leave it to me to make decisions about whether I take them for a swim or to the park, what I give them to eat for lunch and whether to reprimand them if they are being cheeky. This vesting of discretionary power is essential to trust, but it also renders the truster vulnerable to the trusted's incompetence, negligence, or ill will, and the thing entrusted vulnerable to damage or harm.

\footnotetext{
${ }^{6}$ For Baier it is this extra factor of reliance on another's good will that distinguishes trust from mere reliance, and explains why we feel betrayed, rather than merely disappointed when someone fails to do what we trusted them to do. While most trust theorists agree that trust is a species of reliance, one issue of contention in philosophical debates about trust is whether Baier is correct that reliance on another's good will is what distinguishes trust from other forms of reliance.
} 
This analysis of the vulnerability involved in trust raises two questions. First, why do we trust given the potential risks it poses both to ourselves and to the things we value? Baier's answer points to a more fundamental, ontological vulnerability to which trust is a response - because the human condition essentially involves need and interdependence. Baier turns on its head the contractarian assumption that moral obligation arises from voluntary agreements between adults. Rather, she argues, moral obligation arises from unequal relations of need and dependency. ${ }^{7}$ The inescapability of trust and the vulnerabilities it entails are rooted in the innate, primitive and basic trust and love that infants must feel for their parents if they are to thrive. 'Infant trust, although extreme in the discrepancy of power between the truster and the trusted, is to some extent a matter of mutual trust and mutual if unequal vulnerability' $(1986,242)$. Infants are of course maximally (ontologically) vulnerable to the discretionary power vested in their parents to take care of all the goods necessary for them to thrive. Hence they are maximally (pathogenically) vulnerable to neglect, abuse and harm at the hands of their parents. But parents are also (ontologically) vulnerable to the extent that, in a loving parent-child relationship, the child's good is also the parent's good. The case of basic infant trust also points to the non-voluntary nature of many relations of trust. In Baier's view, we do not decide or will to trust. Basic trust is unconscious, automatic, unchosen and not verbally expressed. Other trust relations 'can come with no beginnings, with gradual as well as sudden beginnings, and with various degrees of self-consciousness, voluntariness, and expressness' (240). The same applies to the accepted vulnerability involved in trust.

The second question raised by Baier's analysis concerns the conditions under which it is wise or unwise, rational or irrational to trust, given the power asymmetries and consequent exposure to pathogenic forms of vulnerability inherent in many trust relations. In response to this question, Baier proposes a moral test for trust, which 'amounts to a check on the will and good will of the truster and trusted' (257). If the trust relation relies on psychological motives or qualities of either truster or trusted that, if made known to the other, would undermine or destroy trust, then the trust relation is morally corrupt. For example, if the trust relation is sustained by one

\footnotetext{
${ }^{7}$ This is also a central theme in feminist work on dependency, need and the ethics of care. See e.g. Kittay (1999); Miller (2012).
} 
party's threat advantage over the other or by the other's powerlessness or subservience, or if it is sustained by concealment of breaches of trust, or by the truster's servility, endless forgiveness or unreciprocated generosity, then it is morally corrupt. For such motives or qualities undermine the confident reliance in another's good will that Baier regards as central to trust.

Karen Jones (1996, 2004, 2019) modifies and extends Baier's analysis in several ways that further illuminate the interrelations between vulnerability, trust and distrust. First, extending Baier's notion of 'confident reliance', Jones argues that trust is an affective attitude, rather than a belief that the trusted is trustworthy. ${ }^{8}$ The affective attitude characteristic of trust is an attitude of optimism in the other's goodwill and competence, and an expectation that the one trusted 'will be directly and favourably moved by the thought that you are counting on her' $(1996,6)$. In having this expectation as a truster, I count on the trusted 'recognizing and responding to my vulnerability at the hands of their agency' $(2019,957)$. In trust, then, although the risk involved in acceptance of one's vulnerability is implicitly acknowledged by both truster and trusted, the affective salience of this risk for the truster is minimised by virtue of the attitude of optimism. By contrast, in distrust, which is characterised by pessimism about the other's good will and competence, the salience of this risk is foregrounded. Hence, 'trust and distrust are opposite ends of a spectrum of possible affective attitudes that we can take towards our potential vulnerability at the hands of other agents' $(2019,956)$. Vulnerability to others and the risks of harm this vulnerability entails are thus central to both trust and distrust; what varies is its affective salience.

Jones' characterisation of affective attitudes draws on contemporary emotions theory, and in particular quasi-perceptual theories of the emotions (see e.g. Calhoun 1984; Roberts 1988; de Sousa, 1987). According to these theories emotions, like

\footnotetext{
${ }^{8}$ The claim that trust is an affective attitude rather than a doxastic state is not uncontroversial among trust theorists. I am persuaded by the affective attitude analysis because I am persuaded by the quasi-perceptual account of emotions on which this view is based and I also think it accounts better for the evidence-resistance of trust (as discussed in the following paragraphs). It is beyond the scope of my concerns in this paper to provide a detailed argument in support of this view. For a defense of the alternative view that trust is a belief that the trusted is trustworthy see e.g. Hieronymi (2008).
} 
perceptions, provide us with information about the world as seen from a particular perspective. This perspective incorporates an evaluatively-laden interpretative framework, schema, or way of seeing the world and other agents. This framework directs our attention to certain features of the world, or to certain actions or characteristics of other agents, making these features salient, others less salient. For example, if I feel angry with a person, it may be because I perceive them as having acted unjustly or rudely towards me. My anger directs my attention to certain features of this situation, to certain actions, utterances, or characteristics of the other person, making these features salient to me, others less salient. Thus 'emotions are determinate patterns of salience among objects of attention, lines of inquiry, and inferential strategies' (de Sousa, 1987, 137). To say that trust and distrust are affective attitudes is to that say that they function as 'affective lenses' (Jones 2019, 959), shaping the way we perceive our potential vulnerability to others and the risks attendant upon that vulnerablity.

A second important aspect of Jones' view is her attention to the phenomenology of trust and distrust, specifically the sense of security characteristic of trust and the sense of insecurity characteristic of distrust. Citing the evidence from psychological attachment theory, she suggests that those who are appropriately secure in their attachments 'have characteristic patterns in their trust of others' $(2019,963)$. By contrast, those who are insecure or avoidant in their attachments are more likely to be wary of trust and vigilant of the risks of trusting others. Her notion of 'basal security' (2004) - 'a generalized underlying affective stance towards the prospect of risk at the hands of other agents' $(2019,963)$ - aims to capture the distinctive phenomenology of trust and distrust. In a situation of trust involving the same degree of vulnerability and risk, a person with high basal security will not regard this risk as a threat, whereas a person with low basal security 'lives in continual awareness of her own vulnerability' (964).

The affective attitude analysis and the notion of basal security help to explain the puzzling phenomenon of the evidence-resistance of trust and distrust. Because these attitudes are 'affective lenses' through which we perceive and interpret others' behaviour, motives and character, they filter the evidence to which we attend. A woman with high basal security who feels secure in her attachment to her partner is 
unlikely to look for, or notice evidence of his infidelity, and will be highly resistant to evidence that might shake her trust. If the evidence becomes overwhelming and her trust is finally shaken, the affective lens through which she interprets his behaviour, motives and character will shift in focus. A woman with low basal security who feels insecure in her attachment will be constantly on the look out for evidence of his infidelity, even if the evidence is slender or non-existent. ${ }^{9}$ Hence, 'trust and distrust have a tendency to seek out evidence for themselves and so to be, to a degree, selfconfirming' (Jones 1996, 17). In a later paper, Jones refers to the self-confirming and self-reinforcing character of these affective attitudes as 'affective looping': 'Affective looping occurs when a prior emotional state provides grounds for its own continuance, or when it provides grounds for another different but allied emotional state which in turn provides grounds for the original emotional state, which further reinforces the allied emotional state, and so on, in a self-supporting loop' $(2019,956)$.

One of the limitations that Baier acknowledges with respect to her account of trust is its focus on two party interpersonal relations of trust. This focus overlooks the importance of climates and networks of trust in providing the background conditions in which trust can flourish. Jones (2019) argues that affective looping plays a critical role in the creation and perpetuation of such climates of trust and distrust. A sense of confidence and security, and emotions such as esteem and empathy for others, support affective loops that foster and maintain climates of trust. By contrast, climates of distrust are fostered and maintained in affective loops fuelled by emotions of fear and contempt, which direct attention to the potential threats and risks posed by others. Populist politicians, she points out, understand very well how to manufacture such climates of distrust. In doing so, they turn our awareness of the inescapable

\footnotetext{
${ }^{9}$ Evidence resistance is of course a matter of degree. The degree to which a truster is resistant to evidence that might shake her trust will of course depend on a range of factors, including the extent of her dependence on and affective investment in the relationship with the trusted. In contexts where the truster is less affectively invested, she may be more willing to attend to evidence that might provide grounds for distrust, such as evidence of the trusted's incompetence, negligence or possible betrayal. Thanks to an anonymous referee for pressing me to clarify this point.
} 
vulnerability involved in trust into grounds for suspicion and distrust of others whom they seek to represent as threats to our security. ${ }^{10}$

In the following section, I discuss two examples that illustrate some of the ways pathogenic vulnerability can generate affective pathologies of trust and distrust. In doing so, I draw on several themes in Baier's and Jones' analyses of trust and distrust, specifically Baier's analysis of morally corrupt trust and Jones' idea that trust and distrust are affective attitudes linked to distinctive phenomenologies, emotions and epistemic stances.

\section{Section 3: Pathologies of Trust and Distrust}

The Night Guest (2013), the debut novel of Australian author Fiona McFarlane, is an unsettling story of vulnerability, trust, exploitation, and betrayal. Ruth Field, who has been widowed for five years, is a woman in her mid-seventies living alone in a relatively isolated house on the New South Wales coast. From the outset of the novel questions are raised in the reader's mind about Ruth's mental state. In the opening scene, Ruth awakes in the middle of the night sensing that a tiger is prowling around in her lounge room. Although she suspects she might have been dreaming, she is convinced enough that she can hear the tiger's sniffing, low guttural breathing and yelps to ring her son Jeffrey, in New Zealand, to tell him there is a tiger in her house. She survives the lonely emptiness of her days with small routines and magical thinking. She says to herself that if she counts a pattern of fewer than eight small waves before a bigger one then she will sweep the sand off the path. 'If she had dinner ready in time for the six o'clock news, both of her sons would come home for Christmas...If one person walks on the beach in the next ten minutes, there's a tiger in my house at night; if there are two, the tiger won't hurt me; if there are three, the tiger will finish me off' (6-7).

The morning after her visitation by the tiger, a stranger, Frida, arrives at Ruth's house wheeling a large suitcase and announcing that she has been sent by the government as a carer to help Ruth for one hour a day with her household chores. Frida brings

\footnotetext{
${ }^{10}$ Gilson (2018) makes a similar point about the way the new regimes and discourses of 'securitization' manufacture insecurity and a heightened sense of vulnerability to certain others (e.g. migrants, refugees and asylum seekers).
} 
paperwork to be completed and signed, requesting information about Ruth's personal and financial details. During Frida's visit, Jeffrey calls to check on his mother after the previous night's phone call about the tiger. When she tells him that Frida has been sent by the government to help her, he asks to speak to Frida, and then assures his mother that Frida's help 'could be just exactly what we need' (11). The next day, Frida arrives again in a yellow taxi, driven by George who, according to Frida, is her brother. Within a short period of time Frida has extended her one hour of help to a full morning, filled Ruth's formerly empty pantry with fruit and canned goods so that Ruth no longer needs to go to town to shop, taken over her banking and the payment of bills, supplied her with medication, and persuaded Ruth to sell her late husband's car, which Frida conveniently arranges to sell to Bob, a friend of George's.

Frida's manner towards Ruth alternates between being domineering and sullen or kind and seemingly caring. As Ruth becomes increasingly dependent on Frida, she spends more and more time lost in memories of her childhood and teenage years in Fiji, where her parents were missionaries. She assumes that Frida is from Fiji because of Frida's hair and skin colour, an assumption that Frida neither affirms nor denies. Ruth's memories revolve especially around her first love, Richard Porter, an Australian doctor who she met when she was nineteen and who worked in the clinic with Ruth's father in Fiji. Knowing that his wife had died a year before her late husband Harry, Ruth decides to write to Richard, now living in Sydney, and invites him to stay for the weekend. Frida offers to stay overnight to help during Richard's visit and it is Richard who mentions to Ruth - assuming she already knows - that Frida has moved her things into the room once occupied by Ruth's younger son Phillip. When Ruth confronts Frida about her having moved in uninvited, Frida insists that Ruth had invited her to stay as long as she wanted, refuses to leave the house, and then threatens to leave Ruth for good. Despite being certain that Frida is lying, Ruth also finds it improbable and difficult to believe that Frida would lie to her and worries that her mind is unravelling. Ruth's resistance to countenancing the idea that Frida might not be trustworthy, despite her awareness of evidence to the contrary, points not only to her dependence but also to the extent of her affective investment in the relationship with Frida. 
Frida's gaslighting of Ruth takes a new turn when Ruth becomes convinced one night that the tiger has returned. After initially mocking and teasing Ruth about the tiger, Frida emerges one morning with bloodied arms, telling Ruth she had seen the tiger and it had clawed her arms while she fought it off. Frida then turns to digging holes in the garden all around the house, to trap the tiger, and locks Ruth up inside the house when she goes out so that the tiger won't attack Ruth. As Ruth's mind continues to unravel, she alternates between feeling desperate to escape from Frida and feeling utterly dependent on and grateful towards her. Meanwhile, Ruth's son Jeffrey has finally become sufficiently alarmed by his mother's mental state that he announces he will be coming to visit at the end of the week. This threat precipitates urgent action by Frida. One night she urges Ruth to stay in her room so that she can finally dispatch the tiger, which she does with great noise and commotion. Then the following morning, she takes Ruth into the bank to write a very large cheque, made out to George. At this point, both women's lives completely unravel. Just as Frida has gaslighted and exploited Ruth, George, who is actually Frida's lover, has in turn exploited and hoodwinked Frida into believing that they will share the money and all the other valuables she has stolen from Ruth. But George disappears with the money, leaving Frida bereft and morally devastated by what she has done to Ruth.

In charting Ruth's at first gradual then rapid descent into mental confusion and loss of self, the novel also illuminates the perilous forms of vulnerability that corrupt trust can engender. Although at the outset of the novel Ruth resists Jeffrey's suggestions that she is vulnerable and in need of support, Ruth's willingness to entrust Frida with her care, the sale of her husband's car, and her financial affairs, is a response to her inherent and situational vulnerability - her frailty, isolation, loneliness, and fragile relational connections with her two sons. This vulnerability, which quickly becomes pathogenic as Frida insinuates herself into every aspect of Ruth's life, including her relationships with Jeffrey and Richard, makes Ruth susceptible to a morally corrupt trust relation. Ruth is not completely oblivious to the fact that the trust relation with Frida might be morally corrupt. The narrative makes it clear that at times she suspects Frida's trustworthiness, such as when she is certain that Frida is lying about Ruth having invited her to stay as long as she likes. Hence her trust is vacillating, rather than wholehearted. But this vacillating trust, the uncertain shifts in the affective lenses through which she interprets Frida's behaviour, her alternating feelings of security 
and insecurity with Frida, lead her to distrust herself as much as she sometimes distrusts Frida and makes her especially vulnerable to Frida's manipulation. After Frida has disclosed to Ruth the full extent of her betrayal, she says to Ruth, without it being a genuine question, 'You trusted me, didn't you.' In response to which Ruth thinks to herself that 'she considered it likely that she had never trusted Frida. But then she didn't trust herself' (256). ${ }^{11}$ The affective loops that bind Ruth to Frida thus illustrate the complex emotional dynamics at work in pathological relationships of trust and distrust.

These pathologies in the relationship between the two women are situated in wider pathological relational networks. Jeffrey finds it convenient to accept Frida's miraculous appearance and to trust both in her motives and that she is who she claims to be, despite scant evidence to support these claims. Even when Frida controls his mother's access to him via the phone his suspicions are not roused. Jeffrey's willing acceptance of Frida's assurances and his willingness to entrust his mother to her care, is a morally corrupt form of trust that relieves him of his responsibilities to ensure that his mother is safe and well cared for, and exposes Ruth to pathogenic vulnerability. Frida's vulnerability to George is also pathogenic and enabled by a morally corrupt form of trust. After she has acknowledged her betrayal of Ruth, Frida says of George 'He's taken us for a bloody ride... That bastard has ruined everything...I know George. He'd screw a goldfish if he thought it had any money' (252-3). Yet, over the months she worked and lived at Ruth's house Frida ignored her knowledge of George's character and motives and trusted him blindly to honour his promise that she would be rewarded eventually for her work and the betrayal of Ruth that it entailed. Both Jeffrey and Frida thus willingly fail to confront the question of whether their trust is wise or warranted and ignore evidence that should arouse their distrust, in Frida and George respectively.

Baier suggests: 'If the network of relationships is systematically unjust or systematically coercive, then it may be that one's status within that network will make

\footnotetext{
${ }^{11}$ An anonymous reviewer for this journal has raised the question of whether Ruth's relationship with Frida might be one of dependence or reliance rather than trust. However, the fact that Frida acknowledges that she has betrayed Ruth, rather than merely disappointed her, I think provides support for the view that the relationship is one of trust, albeit a morally corrupt form of trust.
} 
it unwise of one to entrust anything to those persons whose interests, given their status, are systematically opposed to one's own' (1986, 259). My second example investigates the vulnerabilities and pathologies of trust and distrust in contexts of systemic injustice.

Lawrence Hill's powerful novel The Book of Negroes (2007) is the life narrative, told in the first person, of a freed slave, Aminata Diallo. Aminata is a fictional character but the events of her life as recounted in the novel are based on historical slave narratives. The title refers to a handwritten ledger, compiled in 1783 and held in archives in Canada, the US and the UK, containing the names and information about the backgrounds of 3,000 black people - so called 'Black Loyalists' - under British protection towards the end of the American Revolutionary War, who escaped New York harbour on a fleet of over two hundred ships. Some were some freed, some were slaves or indentured servants, but all were promised a new life by the British in Nova Scotia. This promise was not honoured. According to Hill, 'blacks faced outright segregation, were forced to work for wages inferior to those earned by whites for the same work, were kept (in many instances) in slavery or as indentured servants, were largely denied the farming land that they had been promised in exchange for serving the British during the Revolutionary War and were attacked physically during Canada's first anti-black race riot'. ${ }^{12}$ Of the 3,000 who settled in Nova Scotia, around 1,200 formed an African exodus that left Halifax in 1792 on a flotilla of fifteen ships and sailed to Freetown, Sierra Leone. The exodus was set in motion by former Black Loyalists, and organised by British Navy lieutenant John Clarkson.

The novel recounts the life of Aminata, from her kidnap as a child from her home in Bayo, West Africa by slave traders in the mid-1700s, to her enlistment as a Black Loyalist and resettlement in Novia Scotia, to her return to Africa thirty six years after her kidnap, and eventually to her testimony to the British Parliament in 1802 about the horrors of the slave trade. At the outset of the novel she calls her life a 'ghost story'. The story of Aminata and those kidnapped into slavery, is one of almost unendurable suffering and hardship: from the horrors of the slave ships, to

\footnotetext{
12 This quote from Hill and my information about the relevant history are taken from an interview with Hill and historical information written by him, which are included in appendices to the 2011 edition of the novel.
} 
backbreaking work as a slave planting and harvesting indigo, to rape at the hands of her white 'master' Appleby, to the theft and sale of the baby son she had with her slave husband Chekura, to her sale to Solomon Lindo, the indigo inspector for the Province of South Carolina. During the course of her enslavement, Aminata develops sought after skills. She is taught to read in secret by the slave overseer on the indigo plantation and she also learns the skills of midwifery. After her sale to Lindo, she forms a strong attachment to Lindo's wife, Dolly, who encourages her to read widely and to acquire wider knowledge of the world. She also learns accounting skills while working as Lindo's assistant. But after Dolly's death she learns from Chekura, with whom she is briefly re-united after thirteen years' separation, that it was Lindo who sold their son into slavery. It is this betrayal that motivates her, during a trip with Lindo to New York, to flee his service and eventually to join the Black Loyalists.

Aminita is a highly intelligent, resourceful and resilient woman. It is her status as a slave in an abominably unjust and corrupt social system that makes her pathogenically vulnerable to abuse, exploitation and betrayal. Her default stance towards white people is a warranted stance of distrust, but at times in her life she does eventually come to trust some white people, such as Dolly Lindo and John Clarkson. Of the many betrayals of trust experienced by Aminita during her life, perhaps the most devastating is the kidnap from Novia Scotia of May, her three year old daughter to Chekura, by a childless white couple, the Witherspoons. The Witherspoons had hired Aminata to clean for them and do household chores several days a week, and they encouraged her to bring her daughter with her to their home. Although warned not to get 'too close to white folks...they can be fair-weathered friends' $(2007,375)$, Aminata did feel close to the Witherspoons, who loved May and seemed genuinely caring towards Aminata. During the anti-black race riots in the black township of Birchtown, the Witherspoons invite Aminata and May to stay with them in their home in the white township of Shelburne. After four days of rioting, Aminata returns for two days to her home in Birchtown, to see if her house had survived torching and to check on the safety and welfare of her friends, entrusting May to the care of the Witherspoons. But on her return to Shelburne she finds that in her absence the Witherspoons have left on a ship bound for Boston, emptying their home of all its contents and taking May with them. She also discovers that they had been preparing to leave for some time and decided to get out as soon as the riots had ended. Over the 
ensuing months Aminata places advertisements in Boston, New York and Philadelphia, trying to track down the Witherspoons, and she continues searching for information for the next four years, but she can find no trace of either her daughter or the Witherspoons.

The Witherspoons' perspective on their betrayal of Aminita is not disclosed in the novel, since the story is told from Aminata's perspective. No doubt, however, they would justify it to themselves by a self-serving colonial narrative to the effect that they could keep May safe and give her a better life, a narrative that has been repeated in numerous other contexts, such as in the case of Australia's aboriginal 'stolen generations'. ${ }^{13}$ As we have seen, Baier suggests that in a systematically unjust or coercive network of social relationships it may be unwise 'to entrust anything to those persons whose interests, given their status, are systematically opposed to one's own' $(1986,259)$. In other words, in such contexts, default distrust is the wise response. This is a lesson that Aminata learns repeatedly during her life. Yet, given her status first as a slave and then as a freed slave, she often has little choice but to entrust the things she values to the care of others, some of whom repay that trust, as in the case of Dolly Lindo and John Clarkson, some of whom abuse it, as in the case of the Witherspoons. Aminata's story thus illustrates both the inescapability of trust and the inescapable insecurities and risks it entails for those who are pathogenically vulnerable by virtue of their status in a systematically unjust or coercive network of social relationships. It also illustrates the collusion, even if reluctant, of those who occupy privileged positions within this network. After May's abduction, Aminata confronts her other employer, Theo McArdle, about his knowledge of what had happened to May. McArdle, a printer for whom Aminata worked as a typesetter and who paid her secretly for her work, had introduced her to the Witherspoons. It is McArdle who reveals to Aminata that the Witherspoons had been planning to leave for some time and who admits that although he had tried to stop them from taking

\footnotetext{
${ }^{13}$ The term 'the stolen generations' has been adopted by both indigenous and nonindigenous Australians to refer to a generation of Aboriginal children who were taken from their parents under a notorious Australian government 'protection' policy. The children who were removed usually had some white parentage. They were placed in mission schools and trained to become domestic servants in white households or stock and station hands on outback properties. The policy was officially in place until the 1950's and was justified by a similar colonial narrative that removal from their parents was in the children's best interests.
} 
May, he had backed off when the Witherspoons called on the guards on the docks on the grounds that he was causing a disturbance. McArdle knows that he is vulnerable to ill treatment at the hands of white racists for supporting Aminata and it his awareness of this vulnerability that leads him to betray Aminata, however reluctantly. ${ }^{14}$

\section{Conclusion}

The complex interrelations between vulnerability and trust highlight the ambivalence of both vulnerability and trust. Trust is a necessary and inescapable response to ontological vulnerability, and both trust and vulnerability are the source of some of the most profound emotions and human relationships. At the same time, in trusting others we make ourselves vulnerable to them and hence to their possible betrayal, abuse or exploitation of our trust. Pathogenic sources of vulnerability are especially prone to engendering pathologies of trust and distrust that function to compound existing vulnerabilities and enable abuses of trust.

The case of Ruth illustrates the way that inherent and situational vulnerability can engender misplaced trust, which in turns compounds the agent's existing vulnerability and renders her pathogenically vulnerable. The case of Aminata illustrates how pathogenic vulnerability caused by systemic injustice can entangle agents in inescapably risky trust relationships. In such contexts, even if default distrust might be the wisest course of action, risky trust relationships can open up valuable opportunities that might not otherwise be available to an agent, but such relationships also run the risks of endangering what she most values.

My discussion of these two cases has focused on the effects on the vulnerable truster of pathologies of trust and distrust. One important aspect of these pathologies that I have not discussed is the way that agents who are socially marginalised or subject to

\footnotetext{
${ }^{14}$ It might be argued that Aminata's relationships with Dolly Lindo, John Clarkson, Theo McArdle and the Witherspoons are relations of dependence and reliance rather than trust. However, the text makes it clear that, in spite of her justified default stance of distrust, Aminata nevertheless does come to trust these white people over time and hence feels betrayed, rather than merely disappointed, by the Witherspoons and McArdle.
} 
systematic injustice are often treated with presumptive prejudicial distrust by those with social power. As Gerald Marsh argues: 'Being a full participant in the trust economy is a necessary condition for being a full participant in the social realm of cooperative and reciprocal activities' $(2011,286)$. Presumptive prejudicial distrust, which Marsh refers to as 'trust injustice', unjustly excludes those who are presumptively distrusted from the trust economy, impugning their credibility and contributing to 'wider patterns of social injustice and unfairness' (285). For agents who are socially privileged it is easy to be blind to the extent to which our capacities to lead autonomous social lives is made possible by relations of presumptive trust and our inclusion in the trust economy. For agents who are socially marginalised or disadvantaged, presumptive distrust of and by the socially powerful might be the wisest default stance. Recognising the reasons why this might be the case, however, should not blind us to the costs of this stance both for those who adopt it and for wider social climates of trust. ${ }^{15}$

\section{REFERENCES}

Bagnoli, Carla (2018), "Autonomy, Emotional Vulnerability, and the Dynamics of Power", in Berges, Sandrine and Siani, Alberto L. (eds.) Women Philosophers on Autonomy: Historical and Contemporary Perspectives, New York and London: Routledge, pp. 208-225.

Baier, Annette (1986), “Trust and Anti-Trust”, Ethics, 96(2): 231-260.

Butler, Judith (2004), Precarious life: The powers of mourning and violence. London: Verso.

Calhoun, Cheshire (1984),"Cognitive Emotions?", in Calhoun, Cheshire and Solomon, Robert (eds): What is an Emotion? Classic Readings in Philosophical Psychology, New York: Oxford University Press.

Coyle, Alyson (2016), "Some of Us Are Vulnerable But Some Are More Vulnerable than Others: The Political Ambiguity of Vulnerability Studies, an Ambivalent Critique", Critical Horizons, 17(2): 260-277.

de Sousa, R. (1987), The rationality of emotion, Cambridge: MIT Press.

Fineman, Martha Albertson (2010), "The vulnerable subject and the responsive state", Emory Law Journal 60(2): 251-275.

\footnotetext{
${ }^{15}$ Thanks to the anonymous reviewers for this journal for helpful comments on an earlier version of this paper.
} 
Fineman, Martha Albertson (2008), "The Vulnerable Subject: Anchoring Equality in the Human Condition", Yale Journal of Law \& Feminism 20(1): 1-23.

Gilson, Erinn (2011), "Vulnerability, Ignorance, and Oppression", Hypatia 26(2): 308-332.

Gilson, Erinn (2018), "Beyond Bounded Selves and Places: The Relational Making of Vulnerability and Security", Journal of the British Society for Phenomenology, 49 (3): 229-242, DOI: 10.1080/00071773.2018.1434972

Goodin, Robert (1985), Protecting the Vulnerable: A Reanalysis of Our Social Responsibilities, Chicago: University of Chicago Press.

Hill, Lawrence (2007), The Book of Negroes, Toronto: Harper Collins.

Hoffmaster, C.B. (2006), "What does vulnerability mean?”, Hastings Center Report 36(2): 38-45.

Hurst, Samia A. (2008), "Vulnerability in Research and Health Care; Describing the Elephant in the Room?", Bioethics 22(4): 191-202.

Hieronymi, Pamela (2008), "The Reasons of Trust", Australasian Journal of Philosophy, 86(2): 213-236.

Jones, Karen (1996), “Trust as an Affective Attitude”, Ethics 107(1): 4-25.

Jones, Karen (2004), “Trust and terror”, In DesAutels, Peggy and Walker, Margaret (eds.), Moral psychology: Feminist ethics and social theory, Lanham: Rowman and Littlefield, pp. 3-18.

Jones, Karen (2019), "Trust, distrust, and affective looping", Philosophical Studies 176: 955-968, https://doi.org/10.1007/s11098-018-1221-5

Kittay, Eva F. (1999), Love's labour: Essays on women, equality and dependency. London, Routledge.

Kohn, Nina A. (2014), "Vulnerability Theory and the Role of Government", Yale Journal of Law and Feminism, 26(1): 1-28.

Luna, Florencia (2009), "Elucidating the concept of vulnerability: Layers not labels", International Journal of Feminist Approaches to Bioethics 2(1): 121-139.

Marsh, Gerald (2011), "Trust, Testimony, and Prejudice in the Credibility Economy", Hypatia 26(2): 280-293.

McFarlane, Fiona (2013), The Night Guest, Penguin: Melbourne.

MacIntyre, Alasdair (1999). Dependent Rational Animals: why human beings need the virtues, Chicago: Open Court. 
Mackenzie, Catriona (2014), "The Importance of Relational Autonomy and Capabilities for an Ethics of Vulnerability", in Mackenzie, Catriona, Rogers, Wendy, Dodds, Susan (eds.), Vulnerability: New Essays in Ethics and Feminist Philosophy, New York: Oxford University Press, pp. 33-59.

Mackenzie, Catriona (2017), 'Vulnerability, Needs and Moral Obligation', in Straehle, Christine (ed.) Vulnerability, Autonomy and Applied Ethics, New York and London: Routledge, pp. 48-67.

Mackenzie, Catriona (forthcoming), 'Vulnerability, Exploitation, and Autonomy', in Childress, James and Quante, Michael (eds.), Thick (Concepts of) Autonomy: Personal Autonomy in Ethics and Bioethics, Springer.

Mackenzie, Catriona, Rogers, Wendy, Dodds, Susan. 2014, "What is Vulnerability and Why Does it Matter for Moral Theory?", in Mackenzie, Catriona, Rogers, Wendy, Dodds, Susan (eds.), Vulnerability: New Essays in Ethics and Feminist Philosophy, New York: Oxford University Press, pp. 1-29.

Macklin, Ruth (2003), "Bioethics, Vulnerability and Protection", Bioethics 17(5-6): 472-486.

McLeod, Carolyn (2020), "Trust", The Stanford Encyclopedia of Philosophy, ed. Edward N. Zalta, http://plato.stanford.edu/entries/trust/.

Martin, Angela, K., Tavaglione, Nicolas, Hurst, Samia (2014), "Resolving the Conflict: Clarifying 'Vulnerability' in Health Care Ethics:", Kennedy Institute of Ethics Journal 24(1): 51-72.

Miller, Sarah Clark (2012), The Ethics of Need: Agency, Dignity and Obligation. New York: Routledge.

Nickel, Philip (2006), "Vulnerable Populations in Research: The Case of the Seriously Ill”, Theoretical Medicine and Bioethics 27(3): 245-264.

Nussbaum, Martha (2006), Frontiers of Justice: Disability, Nationality, Species Membership. Cambridge, MA: Harvard University Press.

Ricoeur, Paul (2007), “Autonomy and vulnerability”, in Paul Ricoeur, Reflections on the just, trans. D. Pellauer. Chicago: University of Chicago Press.

Roberts, Robert C (1988), "What an Emotion is: A Sketch", The Philosophical Review, 98 (2), 183-209.

Rogers, Wendy, Mackenzie, Catriona, Dodds, Susan (2012), "Why Bioethics Needs a Concept of Vulnerability", International Journal of Feminist Approaches to Bioethics, 5 (2): 11-38.

Sellman, D. 2005, "Towards an understanding of nursing as a response to human vulnerability", Nursing Philosophy, vol. 6, no. 1, pp. 2-10. 
Turner, Bryan. S. (2006) Vulnerability and human rights. University Park, PA: Penn State University Press.

Wolff, Jonathon and de Shalit, Avner (2007), Disadvantage, Oxford: Oxford University Press.

Wrigley, Anthony (2015), “An Eliminativist Approach To Vulnerability”, Bioethics. 29 (7): 478-487. 